\title{
THINKING OUTSIDE THE (WITNESS) BOX: INTEGRATING EXPERTS INTO JURIES TO MINIMISE THE EFFECT OF RAPE MYTHS IN SEXUAL VIOLENCE CASES
}

\author{
Amelia Erin Retter
}

The criminal justice system's response to sexual violence has been increasingly recognised as an area needing attention. In particular, rape myths have a significant impact on whether a victim is believed or not, and this extends to the jury. Due to the potential effect of misconceptions about sexual violence on the jury's decision-making process, alternatives and additional tools have been suggested to minimise this impact. This article looks at options for moving forward such as increasing education and guidance for the jury, as well as changing the fact-finder, but ultimately advocates a new approach of integrating experts with knowledge about sexual violence and its realities into the jury itself. This would allow for responses tailored to each case to create an educative mechanism while maintaining lay participation, and have decisions that are based on accurate understandings of sexual violence.

\section{INTRODUCTION}

The jury has a place in the collective mind of society as a mainstay of the criminal justice system. Nevertheless, recent years have seen proposals to remove the jury in cases of sexual violence. There are fears that due to the prevalence of stereotypes and misconceptions regarding sexual violence, the jury is ill-equipped to adjudicate accurately in these instances.

In 2015, the New Zealand Law Commission examined potential solutions to respond to the challenges of using juries in sexual violence cases. The Commission examined a number of options, which included alternatives to trial by jury such as judge-alone trials and expert panels. However, these too pose challenges, not least of which are concerns about losing the benefits of group

Submitted as part of the LLB (Hons) programme at Victoria University of Wellington. I would like to thank my supervisor, Associate Professor Yvette Tinsley, for her invaluable guidance and support. 
deliberation and community input into the criminal justice system. Given juries provide several benefits that most people in New Zealand hold to be important for a well-functioning, democratic justice system, this article argues that, instead of removing the jury, it is worth exploring ways to improve its function in sexual violence trials.

This article identifies three avenues to address the challenges presented by using juries in these cases. First, to provide additional tools to the jury, including greater guidance through judicial directions, expert evidence on rape myths, and education. Second, to alter New Zealand's approach to sexual violence by changing the fact-finder in all cases, either to experts or judges. Lastly, to combine aspects of these approaches by modifying the structure of the jury itself by embedding experts in the jury to enhance deliberations.

The article argues that greater use should be made of experts to minimise the impact of rape myths but also that lay participation should be retained. Therefore, the third approach suggesting the integration of experts into juries should be explored as a way of making the most of the strengths of both groups (experts and lay people) while still addressing the problem.

\section{BENEFITS OF JURIES}

Juries have multiple functions that are meaningful and symbolically important in a democratic society, and these should be factored into any decision to remove the jury, even considering the challenges its use poses.

The jury provides an outlet for community views to be expressed and encourages input of shared values into the criminal justice system. The use of juries enables a connection between the law and those it protects by taking into account that community's preferences and views. ${ }^{1}$ While it is questionable whether a panel of 12 people can ever truly represent the intricacies and diverse beliefs of a community, ${ }^{2}$ the jury still allows for individuals different from each other to have equal input into the criminal justice system.

Further, juries encourage public confidence in the criminal justice system, and direct participation such as jury service gives a sense of fairness since individuals feel involved. ${ }^{3}$ Public confidence is crucial in legitimising the processes and decisions of the system. ${ }^{4}$ Lay participation embraces popular

1 Paul Fitzpatrick "The British Jury: An Argument for the Reconstruction of the Little Parliament" (2010) 6 CSLR 1 at 2.

2 Tatjana Hörnle "Democratic Accountability and Lay Participation in Criminal Trials" in Antony Duff and others (eds) The Trial on Trial: Judgment and Calling To Account (Hart Publishing, Oxford, 2006) vol 2135 at 142 .

3 Penny Darbyshire "The Lamp that Shows Freedom Lives - Is it Worth the Candle?" (1991) Crim LR 740 at 745 .

4 Fitzpatrick, above n 1, at 1. 
opinion in a system which is otherwise difficult for ordinary citizens to directly influence. ${ }^{5}$ Consequently, the public accepts the system's judgments because the decisions are made by a body composed of people like them. ${ }^{6}$ The public may be more trusting of a group of individuals similar to themselves than a small group of professional judges who represent only part of the community.

The public participation element of juries also acts as a check on the government. The jury provides an opportunity to protect the rights of the defendant from the power of the state. ${ }^{7}$ Juries may see the actual human impact of laws that Parliament does not and may choose not to apply them when the desire to follow the law is overridden by the belief that it would be unjust to punish the defendant. ${ }^{8}$ In doing so, juries can safeguard against unjust laws and punishment in order to protect individual liberty. ${ }^{9}$ Unlike a judge, juries do not have professional duties and constraints that may prevent them from refusing to apply oppressive or unpopular laws. ${ }^{10}$ Such a check is vital because the state is far more powerful than the individual.

Finally, juries have an educative function, allowing participants to learn more about the justice system and society. Jury service can build empathy for fellow citizens by encouraging jurors to see the lives of others and hear their experiences. ${ }^{11}$ Furthermore, jury service can lead to an electorate which is better informed about crime and the justice system, having a moderating effect on public discourse around law and order. ${ }^{12}$ With increasingly punitive attitudes present in the public, jury service could soften attitudes towards the justice system if it and those who are subject to it are better understood by voters. Nevertheless, it is likely that jury service will only have a limited influence on education of the electorate as jury duty is uncommon and short. ${ }^{13}$ Still, those who do have the opportunity to be on a jury may be positively impacted by their experience and use it to educate others, broadening the educative impact. Further, even if the experience was not positive in the eyes of the juror, they will have at least engaged with the courts and the justice system where they otherwise may not have.

5 At 3 .

6 Arthur L Burnett "Jury Reform for the $21^{\text {st }}$ Century: A Judge's Perspective" (2005) 20 Crim Just 32 at 33.

7 At 33 .

8 Lord Devlin "The Conscience of the Jury" (1991) 107 LQR 398 at 403.

9 Simon Bronitt and Russell Hogg "The 21st Century Jury: The Rhetoric and the Reality" (2003) 15 Legaldate 1 at 2 .

10 Fitzpatrick, above n 1, at 2.

11 Sherman J Clark "The Juror, the Citizen, and the Human Being: The Presumption of Innocence and Burden of Judgment" (2013) 8 Crim L \& Phil 421 at 428.

12 Albert W Dzur "Participatory Democracy and Criminal Justice" (2012) 6 Crim L \& Phil 115 at 127.

13 Clark, above n 11, at 429 . 
The benefits presented by juries provide justification to remedy issues with the jury in sexual assault trials, rather than just removing them entirely. Consequently, these strengths should be kept in mind when assessing options. On the other hand, despite these benefits, Part III of this article will show that there are difficulties in relation to juror decision-making in sexual assault trials.

\section{CHALLENGES IN SEXUAL ASSAULT CASES}

Notwithstanding the general benefits of the use of jury trials the seeming reluctance of juries to convict in cases of sexual assault has raised questions as to whether the jury is the appropriate mechanism for determining guilt in these cases. The Law Commission acknowledged that as an area rife with misconceptions, sexual assault cases may be unsuitable for lay fact-finders. ${ }^{14}$ Despite some discussion of alternatives to the jury, the Commission ultimately made no recommendation. To assess the best way forward, and before evaluating alternatives, it is important to understand the features which may make the jury potentially unsuitable in this area of criminal wrongdoing.

Unfortunately, sexual assault is a prevalent problem. The 2014 New Zealand Crime and Safety Survey found six per cent of men and almost a quarter of women had experienced sexual violence in their lives. ${ }^{15}$ Despite the high number of individuals who experience sexual violence, few cases find their way to court, with the Law Commission suggesting many victims do not report offending against them for various reasons, including the perception that a guilty verdict will be unlikely to be obtained. ${ }^{16}$ It is not only reporting which is affected, because if officials believe that a jury will be unwilling to convict in certain cases (such as sexual assault) then fewer of these cases will be prosecuted. ${ }^{17}$ Even where officials do not themselves believe the stereotypes that may lead a jury to acquit, they allow likely jury reactions to influence their exercise of discretion on whether to proceed with the case. ${ }^{18}$ The New Zealand prosecution guidelines state that there must be a "reasonable prospect of conviction". ${ }^{19}$ Therefore, attitudes of those on the jury in rape cases are integral to the overall treatment of the case, from reporting to prosecution. Of course, there are other factors which also affect the decision of whether to proceed with prosecution in rape cases, including the court

14 Law Commission The Justice Response to Victims of Sexual Violence (NZLC R136, 2015) at 114.

15 New Zealand Crime and Safety Survey "Research and Data: Sexual Violence" (7 September 2016) Ministry of Justice <www.justice.govt.nz>.

16 Law Commission, above n 14, at 27.

17 Mike Redmayne "Theorizing Jury Reform" in Antony Duff and others (eds) The Trial on Trial: Judgment and Calling To Account (Hart Publishing, Oxford, 2006) vol 299 at 102.

18 Kimberly A Lonsway and Joanne Archambault "The 'Justice Gap' for Sexual Assault Cases: Future Directions for Research and Reform" (2012) 18 Violence Against Women 145 at 159.

19 Crown Law Solicitor General's Prosecution Guidelines (2013) at 7. 
process itself which is often not sensitive to victims' needs. ${ }^{20}$ Victims may also withdraw complaints or not report if they are aware of the difficulties the criminal justice system has in prosecuting sexual violence cases. ${ }^{21}$ While it is clear the perception that juries will be unlikely to return a guilty verdict does not operate alone, it is an issue that should be addressed as one part of the wider context to attempt to improve the criminal justice response to sexual assault victims in New Zealand.

If sexual assault cases do reach the trial stage, the main role of the jury is to find fact. Juries are allocated this function due to their ability to make judgements about behaviour, owing to their position as members of society and their collective capacity as 12 individuals with diverse backgrounds. ${ }^{22}$ The strength of juries is said to be in that individual misunderstandings or biases can be overcome through the collective decision-making process. During deliberations and interactions between jurors, there are opportunities for misconceptions to be addressed, ${ }^{23}$ and errors in thinking on the part of individual members of the group can be identified and discarded using collective knowledge. ${ }^{24}$ Consequently, through this process of identifying misconceptions and correcting them using pooled knowledge, juries will in theory eventually correctly interpret facts, leading to an accurate verdict.

Juries however are sometimes influenced by external considerations that are not part of evidence and are not relevant to legal guilt or innocence. Rape myths are a particular concern as they can impact the ability of jurors to comprehend evidence correctly. Rape myths are a collection of related misconceptions and stereotypes about what a "real" rape is, ${ }^{25}$ based on judgements regarding how women should act and appropriate sexual conduct. ${ }^{26}$ These usually do not align with reality. ${ }^{27}$ Myths about the offender, victim and circumstances of the crime ${ }^{28}$ all influence whether a juror believes the

20 Elisabeth McDonald and Rachel Souness "From 'Real Rape' to Real Justice in New Zealand Aotearoa: The Reform Project" in Elisabeth McDonald and Yvette Tinsley (eds) From "Real Rape" to Real Justice: Prosecuting Rape in New Zealand (Victoria University Press, Wellington, 2011) 31 at 39.

21 Margaret A Wilson and Angela Scholes "The Typical Rape: Factors Affecting Victims' Decision to Report" in Jane L Wood and Theresa A Gannon (eds) Public Opinion and Criminal Justice (Willan Publishing, Devon, 2009) 123 at 124 .

22 Michael Hall "Judicial Comment and the Jury's Role in the Criminal Trial" (2007) 11 Can Crim L Rev 247 at 626.

23 Jacqueline Horan Juries in the 21st Century (Federation Press, Sydney, 2012) at 62.

24 Fitzpatrick, above n 1, at 3.

25 Francis X Shen "How We Still Fail Rape Victims: Reflecting on Responsibility and Legal Reform" (2011) 22 Colum J Gender \& L 1 at 14.

26 Law Commission, above n 14, at 25.

27 At 25

28 Shannon M Stuart, Blake M McKimmie and Barbara M Masser "Rape Perpetrators on Trial: The Effect of Sexual Assault-Related Schemas on Attributions of Blame" (2016) Journal of Interpersonal Violence 1 at 8. 
victim's story. ${ }^{29}$ Overall, the effect of the myths is to shift blame to the victim and excuse the offender, ${ }^{30}$ so the victim's version of events will not be believed. Rape myths therefore operate to distort evidence and witness credibility, potentially leading to the fact-finder erring when determining guilt.

The operation of rape myths creates issues for jurors in the decision-making process. Being able to understand and interpret evidence accurately and without prejudice towards the parties is critical to the jury being able to perform their job of determining facts. ${ }^{31}$ Otherwise, the jury's decision will not be credible or robust. Rape myths can frustrate comprehension of evidence and contribute to prejudicial reasoning in a sexual assault context. The ability of the jury to discard and root out inaccurate reasoning relies on at least some jurors being capable of interpreting the evidence free from misconceptions, which is often not the case in the sexual assault context. Juror ignorance of issues related to sexual violence means they have a more limited grasp of the issues at stake in the case and results in a less informed conclusion. ${ }^{32}$ Because the ability of jurors to see evidence objectively may be inhibited by rape myths, the collective decision-making process is less effective in ensuring that erroneous interpretations of information are discarded.

The influence of rape myths is exacerbated by the unclear nature of many sexual assault cases and how juries go about making decisions. In many instances, there is not plentiful hard evidence so juries use external beliefs and narratives to supplement and make sense of limited information. ${ }^{33}$ Sexual assault cases usually involve differing stories presented by the accused and the complainant, ${ }^{34}$ and which story is believed will determine the verdict. Research suggests that juries create stories to aid in sorting evidence and reaching a verdict. ${ }^{35}$ However, general knowledge that is not specific to the case being heard also impacts how information is sorted and how gaps in the narrative are filled. ${ }^{36}$ It is in this process of creating a story that rape myths become influential, as they may change the

29 Law Commission, above $\mathrm{n} 14$, at 25.

30 Judy Shepherd "Reflections on a Rape Trial: The Role of Rape Myths and Jury Selection in the Outcome of a Trial" (2002) 17 Affilia 69 at 70.

31 Joe Stone "Are We Doing Enough to Ensure Juries Understand Expert Evidence and Judicial Directions?" (2017) 4 Arch Rev 5 at 6.

32 Steven I Friedland "The Competency and Responsibility of Jurors in Deciding Cases" (1990) 85 NWUL Rev 190 at 194.

33 Sue Triggs and others Responding to Sexual Violence: Attrition in the New Zealand Criminal Justice System (Ministry of Women's Affairs, September 2009) at viii.

34 Stuart, McKimmie and Masser, above n 28, at 2.

35 William Young "Summing Up to Juries in Criminal Cases - What Jury Research Says About Current Rules and Practice" (2003) Crim LR 665 at 682.

36 Laura McGowan "Trial by Jury: Still a Lamp in the Dark?" (2005) 69 J Crim L 518 at 531. 
standard by which evidence is judged and change the meaning of the evidence. Consequently, rather than stories necessarily fitting the evidence and what is presented at trial, the story constructed may be built by selectively using ideas about what rape should look like. ${ }^{37}$ Rape myths therefore allow jurors to make sense of contradictory stories and attribute blame where it would otherwise be difficult to do so due to lack of concrete evidence. ${ }^{38}$ By assisting in creating a narrative, rape myths aid jurors in determining which story is believed, but distort this determination by introducing erroneous ideas about what rape is, external to the evidence presented in court.

So, do juries really rely on rape myths to reach verdicts? Research has shown that for the most part juries decide on the evidence presented in court and the group will keep discussions to relevant considerations. ${ }^{39}$ However, Dinos and others, in a systematic review of multiple studies, found that eight of nine studies indicated that rape myths do impact decisions of juries. ${ }^{40}$ They further found that an individual was more likely to deliver a not guilty verdict if the individual believed rape myths. ${ }^{41}$ Eliminating the jury's reliance on these extra-legal attitudes and factors depends on the jury as a whole being competent and with sufficiently diverse views to overcome any irrelevant considerations. ${ }^{42}$ The ability to constrain the use of extra-evidential considerations in sexual assault trials using group decision-making with varied views may be limited because rape myths are widely held. ${ }^{43}$ The impact of rape myths on juror decision-making may therefore not be able to be remedied through group consensus.

Problems should not be overlooked because of the positive impacts that juries have in other areas. Those positives should not prevent us recognising issues and taking steps to remedy them. It is therefore worthwhile to look at alternatives or additions to the process that may minimise the impact of rape myths on the decision-making process.

\section{PROVIDING ADDITIONAL TOOLS}

For minimal disruption, it is sensible to investigate whether current shortfalls in the system may be remedied within the existing framework. While some jurors are apathetic or incompetent, most who sit on juries are surprised by how well the process works. ${ }^{44}$ Not only that, but the New Zealand

37 Sokratis Dinos and others "A Systematic Review of Juries' Assessment of Rape Victims: Do Rape Myths Impact on Juror Decision-Making?" (2015) 43 IJLCJ 36 at 39.

38 Stuart, McKimmie and Masser, above n 28, at 2.

39 Young, above n 35, at 671 .

40 Dinos and others, above n 37 , at 45.

41 At 46.

42 Young, above n 35, at 671 .

43 Shen, above $\mathrm{n} 25$, at 25.

44 Peter Thornton "Trial by Jury: 50 Years of Change" (2004) Crim LR 119 at 135. 
Bill of Rights Act 1990 guarantees the right to a trial by jury for offences with a maximum penalty of over two years imprisonment. ${ }^{45}$ Thus to protect defendants and to preserve the benefits to wider society provided by the jury, tools to support jurors in their function should be considered.

\section{A Judicial Directions}

Potentially, judicial directions could be better utilised to guide juries and indicate what is and is not acceptable to consider during deliberations. The purpose of judicial directions is to direct the jury on relevant issues and review evidence that has been presented. ${ }^{46}$ Including directions specifically on rape myths would assist the jury in knowing explicitly what misconceptions about sexual violence should not be used. Requiring directions around the applicability of rape myths may be especially useful as they can be tailored to the specific facts of the case, so jurors only have to adjust thinking about relevant rape myths, rather than receiving large amounts of information that may not actually be pertinent to the case. ${ }^{47}$

A number of jurisdictions have used judicial directions to address the use of rape myths in deliberations. In New Zealand, the only specific direction related to misconceptions about sexual violence is in s 127 of the Evidence Act 2006, providing that the judge may tell the jury that there might be good reasons for delay in reporting or failure to report. However, unlike in comparable jurisdictions such as New South Wales and the Northern Territory, this is at the discretion of the judge. ${ }^{48}$ In Scotland, the Abusive Behaviour and Sexual Harm (Scotland) Act 2016 requires the trial judge to give directions about two specific rape myths when conditions set out in the Act are met. ${ }^{49}$ The myths which juries will be given guidance on relate to delays in reporting (like New Zealand) and lack of physical resistance by the victim or use of force by the offender. ${ }^{50}$ These target specific misconceptions and aim to counterbalance them. Judicial directions may be effective for myths that can be defined and denounced in definite terms, such as the ones targeted in Scotland, which are always false and have no bearing on legal liability. ${ }^{51}$ New Zealand could make further use of directions to clearly tell juries not to consider such myths as they are irrelevant.

Even if directions are given, it does not guarantee they will be effective. The timing of directions is particularly troublesome. Placing the directions about rape myths at the end of the trial (as they

45 New Zealand Bill of Rights Act 1990, s 24(e).

46 Nic Madge "Summing Up: A Judge's Perspective" (2006) Crim LR 817 at 817.

47 Law Commission, above n 14, at 117.

48 The Scottish Government Equally Safe - Reforming the criminal law to address domestic abuse and sexual offences: Scottish Government Consultation Paper (APS Group Scotland, March 2015) at 25.

49 Abusive Behaviour and Sexual Harm (Scotland) Act 2016, s 6.

50 Section 6.

51 Isla Callander "Jury Directions in Rape Trials in Scotland" (2016) 20 Edin LR 76 at 79. 
usually are) impacts on their efficacy. ${ }^{52}$ Misconceptions about rape can influence how evidence is immediately interpreted and understood, so putting directions after opinions of evidence may have already been formed makes the effect of rape myths on decision-making hard to reverse. The jury constructs a narrative from the evidence as it is presented, and this is hard to change once it has been pieced together. Therefore, debunking myths after the evidence has already been presented may limit the effectiveness of directions aimed at dispelling myths.

Repeating and explaining rape myths when giving directions is also a concern. Raising material, including rape myths, reminds jurors of the information and makes it more familiar even if it is being mentioned to be refuted. ${ }^{53}$ Particularly since instructions from the judge often have little impact, ${ }^{54}$ jurors may remember the myth was brought up in the directions but not remember the surrounding context accurately. In this way, judges laying out rape myths may actually reinforce them, increasing their relevance in the minds of jurors and making it more likely they will be relied on when deliberating. Jurors may distort directions to support their pre-existing beliefs about rape, especially if the myth is just described and then only countered with a brief direction. ${ }^{55}$ Consequently, judicial directions on rape myths may do more harm than good and exacerbate the problem of jurors relying on irrelevant misconceptions during deliberation.

Directions would also have to be given and worded correctly. It is more likely directions will be followed if reasons are given for them and it is explained why the beliefs are inaccurate. ${ }^{56}$ Thus the structure and how the directions are presented need attention to increase effectiveness. However, the effectiveness of any judicial directions relating to rape myths would depend on the skill with which judges make the directions understandable. Judges should keep in mind the target audience of lay people. ${ }^{57}$ They should therefore word their directions clearly and simply, without using complex sentence structure. ${ }^{58}$ To be as effective as possible directions should be also given in written form as many issues with comprehension and recall arise from the oral nature of the system. ${ }^{59}$ Written

52 At 79.

53 Jeremy Finn, Elisabeth McDonald and Yvette Tinsley "Identifying and Qualifying the Decision-Maker: The Case for Specialisation" in Elisabeth McDonald and Yvette Tinsley (eds) From "Real Rape" to Real Justice: Prosecuting Rape in New Zealand (Victoria University Press, Wellington, 2011) 221 at 239.

54 At 239.

55 Callander, above $\mathrm{n} 51$, at 80.

56 Marie Comiskey "Initiating Dialogue About Jury Comprehension of Legal Concepts: Can the 'Stagnant Pool' be Revitalized?" (2010) 35 Queen's LJ 625 at 647.

57 Michael G Heyman "Lost in Translation: Criminal Jury Trials in the United States" (2014) 3 Brit J Am Legal Stud 1 at 23 .

58 Callander, above $\mathrm{n} 51$, at 80 .

59 Madge, above n 46, at 818. 
instructions clarify information, reducing requests from juries for explanations or reminders of information given to them. ${ }^{60}$ Jurors provided with written information are better able to understand and recall it than those who were just given the informational orally. ${ }^{61}$ However too much information may overwhelm the jury. ${ }^{62}$ Any written material given to juries should be clear, concise, and relevant, to maximise its usefulness.

It is unlikely directions alone would solve the issues of rape myths and their influence on juror decision-making. The Law Commission does not support adding more statutory directions, partly due to lack of research into their effectiveness. ${ }^{63}$ If statutory, they would also be less flexible; considering ongoing research into rape myths and decision-making by juries, being easily updatable would be an advantage. ${ }^{64}$ Furthermore, it may be inefficient to require formal directions for all myths. ${ }^{65}$ Instead, the Law Commission recommends that judges should have access to potential directions that may be used if appropriate. ${ }^{66}$ Yet more issues are raised by this proposal. Relying on discretionary directions may lead to inconsistency in similar cases depending on the attitude of the judge towards rape myths, and judges may fail to issue instructions where it would be appropriate to do so. ${ }^{67}$ Education of judges could partly address this to ensure that judges understand why they should do all they can to ensure rape myths do not influence juries and encourage them to make use of optional directions. However, judicial directions are not a panacea. Indeed, given the number of challenges in ensuring that directions have a meaningful influence on what juries take into account and that directions may actually reinforce some myths, they may have little impact or even make the situation worse.

Overall, judicial directions are not likely to solve the root issue because they are unlikely to have a significant and comprehensive impact on jury deliberations. This is because they do not necessarily prevent rape myths from being used to assess evidence and come to a decision. Therefore, other measures may be more effective.

\section{B Education}

Improving the jury's understanding of rape myths generally and explaining why they are wrong could solve the issue by making them aware of misconceptions that they might rely on during

60 At 821 .

61 Cheryl Thomas Are Juries Fair? (Ministry of Justice (UK), Research Series 1/10, February 2010) at 38.

62 Comiskey, above n 56, at 654.

63 Law Commission, above n 14, at 118.

64 At 118.

65 Callander, above n 51, at 79.

66 Law Commission, above n 14, at 119.

67 Callander, above n 51, at 79. 
deliberation. The Law Commission suggested information packs could be given out, but ultimately gave no recommendation. ${ }^{6}$ Providing packs that are tailored to each case and relevant rape myths would be inefficient, while generic information may be inflexible and incapable of responding to nuances of individual cases. Not only this, but there is no guarantee that information packs will be at the forefront of jurors' minds while deliberating. The Law Commission additionally expressed some reservations in that to be effective, the education would need to be thorough and ongoing. ${ }^{69}$ Obviously, this is not possible given that juries are selected randomly as the need arises and requiring a lengthy course to improve juror understanding of rape myths would increase the burden on jurors significantly. Not only is this unfair to jurors, but defendants would also have to endure a longer trial process. Additionally, delays to the trial in order to provide education to jurors would be costly to the system and create extra challenges for witnesses and particularly complainants who may be anxious about the process and wish to get on with their lives. So, because education for jurors on rape myths is likely to be short and not necessarily responsive to each case's particularities, it is unlikely to make fundamental changes to juror beliefs that are relied on when deliberating, and thus not successfully remedy the issue. On the other hand, longer and more thorough educational processes are likely to produce unacceptable delays.

\section{Expert Evidence}

Experts could improve the knowledge of jurors by laying out issues related to the case and the realities of sexual violence that may be relevant to the case. The jury's competency is only as good as the evidence given to it in the trial process. ${ }^{70}$ If rape myths are not effectively dispelled, there may be a greater likelihood of decisions being influenced by extraneous considerations. Thus, it is beneficial to ensure that the jury has decent information to use to inform its decision and base it on fact rather than myth. In New Zealand, it is possible to provide the jury with agreed upon expert evidence in a joint statement under s 9 of the Evidence Act. ${ }^{71}$ Doing so can reduce confusion and potential recall difficulties when expert evidence is given orally. The Law Commission suggests that this should be done wherever possible, yet there would be challenges in that the defendant may be unlikely to agree to the admission of evidence as they too are likely to believe in rape myths. ${ }^{72}$ Furthermore, the operation of rape myths is likely to assist the defendant's case, as myths have the effect of shifting blame from the offender to the victim so there is little incentive for the defendant to agree to a statement being issued. Nevertheless, an agreed statement from experts would be beneficial as it would provide a good base from which jurors can work. Because experts are accepted by both sides,

68 Law Commission, above n 14, at 120.

69 At 120 .

70 Thornton, above n 44, at 135.

71 Evidence Act 2006, s 9.

72 Law Commission, above n 14, at 120. 
jurors would also not have to spend time determining the validity of each expert's views. Unlike information packs that may be more general, an agreed statement would be specific to the case in question and so may be a better response to the need for juror education. Agreed statements may however be time-consuming to articulate as the defence and prosecution experts would need to meet to formulate the statement.

Experts reaching consensus on some issues could be incorporated into the trial itself using "hottubbing" or concurrent evidence. The process of hot-tubbing permits experts to discuss pertinent issues before the trial, resulting in a report outlining areas of disagreement. ${ }^{73}$ Experts for each party can then also testify in a discussion setting. ${ }^{74}$ Hot-tubbing allows for expert representation for each side to be maintained while being flexible and responsive to the particular case. ${ }^{75}$ By allowing experts to engage in discussion about the issues, comprehension of potentially confusing issues on the part of the fact-finder could be enhanced. ${ }^{76}$ A pilot programme using hot-tubbing was run in courts in Manchester and found that participants believed that concurrent evidence assisted in increasing understanding to improve decision-making. ${ }^{77}$ Enhancing clarity around the meaning of evidence and the invalidity of rape myths using hot-tubbing may therefore promote decision-making that is not based on rape myths. Edmond is wary of abolishing partisan experts and formal cross-examination in the absence of further research into the matter, but concedes there is potential to facilitate comprehension of issues. ${ }^{78}$ Allowing experts to have a more collegial approach to giving evidence may be a way to encourage rape myths to be clearly addressed and explained to the jury in an accessible manner. Using experts in this fashion may thus assist the decision-making process by debunking myths during evidence and giving all information in an accessible manner in one block that will be easy for jurors to understand. By doing so, confusion may be minimised and jurors prevented from later relying on rape myths.

Relying more on expert evidence would allow lay participation but make participants more informed due to what they have heard from experts. However, if the input of the experts ends before deliberations, there is still no guarantee that attitudes have changed and that once discussions begin jurors will not fall back on rape myths. Even written statements from experts may be disregarded if

73 Yvette Tinsley "Science in the Criminal Courts: Tool in Service, Challenge to Legal Authority or Indispensable Ally?" (2013) 25 NZULR 844 at 862.

74 Freya Kristjanson "'Hot-Tubs' and Concurrent Evidence: Improving Administrative Proceedings" (2012) 25 Can J Admin L \& Prac 79 at 81.

75 Tinsley, above $\mathrm{n} 73$, at 862 .

76 Gary Edmond "Secrets of the 'Hot-Tub': Expert Witnesses, Concurrent Evidence, and Judge-Led Reform in Australia" (2008) 27 CJQ 51 at 59.

77 Hazel Genn "Getting to the Truth: Experts and Judges in the 'Hot-Tub"' (2013) 32 CJQ 275 at 291.

78 Edmond, above n 76, at 81 . 
jurors are not actively and continually reminded of the information contained in documents and its relevance to the evidence they are considering. Additionally, experts referring to rape myths may run into the same issues already discussed under judicial directions, where reference to rape myths may actually reinforce belief in them by drawing attention to them. Furthermore, there are a number of questions around what information should be emphasised or referred to. If experts are to address rape myths, how is it decided which ones are most relevant and to be included in their discussion? Would this be on the parties to raise as points in submissions, the judge as an impartial party, or would the experts themselves select the myths they consider the most relevant?

\section{CHANGING THE FACT-FINDER}

Working within the existing structure by providing education and judicial directions on rape myths is unlikely to be sufficient to make the necessary changes in juror attitudes to prevent rape myths being relied on during deliberations. Consequently, it may be necessary to look at other ways of adjudicating sexual assault cases, without having to rely on lay individuals who hold erroneous beliefs. Juries are not the only mechanism employed to determine facts in the criminal justice system. In fact, some jurisdictions have never used them or have eliminated them. ${ }^{79}$ The Law Commission suggested that someone with specialist knowledge in the field of sexual violence may be better suited to the role of fact-finder, ${ }^{80}$ and considered two alternatives: judges sitting alone and expert panels. That is not to say that there are no other models that could be adopted, such as Germany's model of a lay panel sitting with a judge. The focus in this part will be on the options specifically assessed by the Law Commission.

\section{A Judge-Alone}

Judge-alone trials for all cases of sexual assault would remove all lay input and thus ostensibly also prevent widespread misconceptions in the community influencing verdicts.

The Criminal Procedure Act 2011 (CPA) limits jury trials, so trials in which a judge sits alone are not unusual in New Zealand's criminal justice system. Category one and two offences are automatically heard by judges alone, ${ }^{81}$ and defendants pleading not guilty to a category three offence have the option to elect for trial by jury. ${ }^{82}$ Even for the most serious crimes (category four) where a jury trial is automatic, a judge-alone trial may be ordered in the limited circumstances laid out in ss 102 and 103.83 In terms of sexual assault, the Crimes Act 1961 states the maximum term of

79 Fitzpatrick, above n 1, at 1.

80 Law Commission, above n 14, at 111.

81 Criminal Procedure Act 2011, ss 6, 71 and 72.

82 Sections 6 and 50.

83 Sections 74 and 102-103. 
imprisonment for sexual violation is 20 years, ${ }^{84}$ and the offence does not appear in sch 1 of the CPA. Consequently, most sexual violation crimes are category three, meaning there is the option for trial by jury if the defendant so elects. Since a significant majority of all criminal cases are already heard by a judge alone, there are already clear rules in place to guide such trials. ${ }^{85}$ Implementation would thus be straightforward and the solution would immediately be able to begin to address the challenges in rape trials.

Judges may be better placed to make determinations, especially in areas which require specialist knowledge, like sexual violence, due to their professional skills and the ability to target education towards them. The Law Commission suggested that judges should have a designation to preside over sexual assault trials dependent on completion of training. ${ }^{86}$ Supplementary knowledge to what has already been gained in practice can then be instilled in judges to specifically address issues in instances of sexual violence. Such specific knowledge would mean judges will be more qualified to assess conflicting stories and credibility than a jury would. By being aware of rape myths, judges can understand how they influence the decision-making process and factual determinations and guard against them. This option would be efficient as it is far easier to train a small pool of judges than every jury. ${ }^{87}$ It would be a longer term investment, as judges continue sitting and will hear multiple cases where the education will be relevant, whereas a particular jury only hears one case. ${ }^{88}$ It is also possible for training to be ongoing and respond to new developments in the area of sexual violence, ${ }^{89}$ which would be important to continually ensure that judgments are not based on incorrect information. Educating judges may therefore be a simple way to target education in the criminal justice system to effectively reduce the influence of rape myths and irrelevant considerations on the determination of guilt in sexual assault cases.

Even if education was provided, it would have to be comprehensive and effective, which is not guaranteed. Rape myths are so pervasive that cursory education or limited familiarity with misconceptions may have little effect. Accordingly, unless education for judges is thorough, judges are not necessarily better placed to make determinations in rape trials than an uneducated jury. To reap the benefits of an informed judiciary making robust decisions not based on rape myths, an education programme would have to be carefully created and implemented to ensure maximum value.

84 Crimes Act 1961, s 128B.

85 Law Commission, above n 14, at 115.

86 At 105.

87 At 115 .

88 At 115

89 Finn, McDonald and Tinsley, above n 53, at 242. 
Judges are not necessarily less prejudiced than the rest of society. Rape myths are pervasive and hard to dispel, so even with education there is no guarantee that judges will be any less susceptible to using rape myths to assist in difficult cases. Judges also rely on mental shortcuts due to the complex nature of many cases and the need to make sense of at times confusing evidence. ${ }^{90}$ Thus, in using story building as juries do, judges are subject to the same limitations of this decision-making model. ${ }^{91}$ Some studies of jury behaviour which ask judges about what their decision would have been indicate that for the most part, judges concur with the jury's verdict, ${ }^{92}$ while others find a lower rate of around half. ${ }^{93}$ Either way, in at least some cases, rape myths may be operating on the judge to produce this agreement, so the verdict may be able to be changed by education. But again, there is a real possibility that prejudices may persist due to the widespread acceptance of rape myths.

If judges are prejudiced just as juries are, judge-alone trials may be more dangerous, as there are fewer opportunities for different views to challenge the judge's opinion. There may be less bias in juries as diverse views can balance prejudices out, while judges may never be forced to confront their biases. ${ }^{94}$ The judge does not have the benefit of 11 others questioning their reasoning, ${ }^{95}$ so judges may not be able to critically assess their own views as a juror can when confronted by another juror. Group discussions allow dissimilar interpretations of the same information to be presented by different group members. ${ }^{96}$ However, providing reasoned decisions, including which facts have been accepted by the judge, provides some level of scrutiny which can more easily guard against fact determinations based on extraneous factors. The requirement to provide reasons is a mechanism to hold judges to account which is not applicable to juries who are not required to explain their verdict. ${ }^{97}$ Judges therefore may be forced to more closely consider why they are accepting certain facts as they will have to justify them in writing without reliance on factors like rape myths. In this way, judge-alone trials in sexual assault cases may lead to greater transparency around whether rape myths have had an impact on the verdict.

However, while writing reasoning may help to some degree in requiring the judge to justify and deliberately think through their choices, it does not provide views that the judge has not thought of

90 At 243 .

91 At $233-234$.

92 Heyman, above n 57, at 14.

93 Law Commission Juries in Criminal Trials Part Two - A Discussion Paper (NZLC PP37, 1999) at 68.

94 Richard O Lempert "Citizen Participation in Judicial Decision Making: Juries, Lay Judges and Japan" in Valerie P Hans (ed) The Jury System (Ashgate Publishing, Farnham, 2006) 133 at 129.

95 Thornton, above n 44, at 135.

96 Fitzpatrick, above n 1, at 4.

97 Douglas Brown "Some Recent Criticisms and Problems of Trial by Jury" (1974) 11 UW Austl L Rev 256 at 162. 
themselves. With only one outlook contributing to the reasoning, it may be hard for that person to appreciate and give appropriate weight to alternative explanations. Even if judges are confident in their abilities to discern the truth, we cannot be sure that their decision is a result of skill or whether it is a result of the use of rape myths. ${ }^{98}$ Thus group decision-making presents an opportunity for biases to be more effectively challenged. These views are likely to be more varied than that of the judiciary, as judges are not usually representative of the community. ${ }^{99}$ The jury's collective experiences provide a broader basis for making determinations of credibility than does a single judge. ${ }^{100}$ Nevertheless, as mentioned, since rape myths are so established in society, there is no guarantee that in sexual assault trials group deliberations or a diverse decision-making body will lead to a more reasoned result, as all members of the group may be influenced by the same rape myths. Acknowledging this makes a judge-alone trial not substantially different for jury trials in that only a limited view in terms of rape myths would be present.

Additionally, a judge sees all the evidence, even when in a jury trial it would be inadmissible. Knowing this extra information may create an unconscious bias. A judge sitting alone must hear all the evidence and decide what is and is not relevant. ${ }^{101}$ While it would be ideal to think that a judge would be able to act professionally and put this aside, in reality it is likely that it would be extremely difficult to totally disregard such evidence when making a decision. ${ }^{102}$ There is a risk of replacing one set of irrelevant considerations with another, rather than building a fairer method of determination in cases of sexual assault.

Moreover, a judge also lacks the anonymity that the jury enjoys. They may therefore be more open to personal attack for their decisions and feel greater pressure to align with the dominant societal views of what the outcome of a case should be if it is highly publicised. ${ }^{103}$ On the other hand, judges routinely make decisions that do not necessarily match the views of the public which may be regarded as unpopular and consequently this objection is likely to be of only minor concern.

Obviously, relying solely on a judge in a sexual assault trial negates the benefits of a jury. Introducing a system from which the jury is removed would lose these benefits for no substantial gain, because judges are also susceptible to rape myths, particularly if education is not effective and comprehensive. Judge-alone trials therefore will not necessarily solve the problem that has been

98 Emma Cunliffe "Judging, fast and slow: using decision-making theory to explore judicial fact determination" (2014) 18 E\&P 139 at 160.

99 Bruce Houlder "The Importance of Preserving the Jury System and the Right of Election for Trial" (1997) Crim LR 875 at 879.

100 Hall, above n 22, at 262.

101 Law Commission, above n 14, at 59.

102 Fitzpatrick, above n 1, at 11.

103 At 11. 
identified. Ultimately, judge-alone trials are subject to similar issues as juries without the benefits and with added challenges. Although there are some benefits to judge-alone trials, they are not a significant improvement on juries in addressing the problems raised in Part III while also having the added drawback of losing the benefits identified in Part II. Consequently, other ways to limit the impact of rape myths are considered.

\section{B Expert Panels}

Features like group decision-making and different perspectives that make the jury valuable would be retained to some degree by the option of expert panels suggested by the Law Commission. They would take the role of fact-finder and members would be required to have some knowledge in the area of sexual violence. ${ }^{104}$ An expert panel would act like a jury but would not be one in the conventional sense. Expert knowledge of sexual violence would allow the decision to be based on the evidence itself, rather than misconceptions that may influence how the evidence is interpreted. ${ }^{105}$ Furthermore, collective decision-making among the assessors would be possible, avoiding the issue of a judge-alone trial where only one point of view is available and would not be challenged. ${ }^{106}$ In this way, a type of specialised jury is constructed which maintains the benefits of multiple points of view whilst ensuring that these points of view are not coloured by irrelevant considerations like rape myths. Some level of non-legal community participation would be preserved, yet decisions would be based on a better understanding of the information presented at trial.

Nevertheless, requiring expertise to be part of the "jury" fundamentally changes what the jury as a panel of lay representatives is meant to be. Jurors are not meant to have any prior knowledge and come to the trial with no expertise, therefore making the decision based solely on evidence presented in court. ${ }^{107}$ The issue is however that external factors do influence juror decision-making in sexual assault trials and so determinations are not made solely on evidence presented during the trial. If prior knowledge is going to be used in sexual assault trials, perhaps external knowledge which is accurate is needed so that gaps in evidence are not filled with myths.

Although competency is enhanced, diversity of views on the panel may be sacrificed. Expert panels acting instead of a jury would limit the expression of community participation and diverse opinions since there may be professional consensus on issues. As already mentioned however, due to the presence of rape myths, views of jurors are usually homogenous so a normal jury in a sexual assault case would also be limited in diversity of views. Furthermore, professional concurrence may indicate accuracy of views or, at minimum, the most accurate available at the time of adjudication.

104 Law Commission, above n 14, at 115.

105 At 116 .

106 At 116.

107 Friedland, above n 32, at 194. 
Additionally, just because professionals have a shared understanding about the realities of sexual assault does not necessarily mean that they will have the same assessment of what the verdict should be. Differences would however be based on more accurate views of sexual assault, and consequently be more valid than opinions based on misconceptions. There is also a danger that when there is not consensus, panellists may engage in professional debates about issues rather than discussing the evidence itself, which highlights the importance of lay participants and their more practical approach.

Expert assessors may be a solution to prevent rape myths unduly influencing determinations of guilt or innocence. The existing jury model could be used but lay persons would be replaced with those with specialist knowledge. Processes could be similar and not require significant adjustment. Expert panels are also an improvement on judge-alone adjudications because they employ group decision-making and a diversity of views based on accurate understandings of circumstances around sexual violence, the latter of which also makes them an improvement on traditional juries. There could be more confidence that verdicts are not reached on the basis of misapprehension about the realities of sexual violence. However, the community input of lay juries and associated benefits of public confidence in the system are lost.

\section{A NEW APPROACH: INTEGRATING EXPERTS INTO THE JURY}

Since experts fundamentally improve the situation by being aware of misconceptions and not relying on them, they are well placed to provide solutions to the issue of rape myths in sexual assault trials. However, they also lack true community input and the associated benefits which were emphasised at the beginning of this article as being important to take account of. Using experts while retaining benefits of lay participation may, therefore, be the ideal way to address the problem and allow decision-making to be both informed and participatory.

Common issues with potential solutions discussed above are that providing information (in whichever form) either may not be relevant to a particular case or may not address specific biases that participants have. Further, there are concerns that some solutions will negate the benefits of community involvement in justice. Accordingly, it is necessary that solutions simultaneously provide accurate information, retain public input, and are responsive to the needs of both the case and the particular misconceptions that lay participants believe. One such solution would be to have information provided to jurors that is specific to the case they are considering and responsive to reasoning they may put forward that relies on rape myths. By embedding experts into the jury as part of the decision-making body, information can respond in real time to any erroneous reasoning used by jurors and provide accurate contrary views where otherwise opinions may be homogenous. Doing so also means that the information is integrated rather than artificially injected into deliberations, and there is no need to predetermine which rape myths should be addressed, which could lead to inconsistency across cases or omissions. 
A jury of professionals and ordinary citizens would allow community participation and articulation of values as well as make use of input by specialists in the relevant field. A few individuals with expertise in the area of sexual violence could be drawn from a separate pool and be integrated with the rest of the jury. Chappell suggests that the process of deliberation allows people to be influenced or swayed by the arguments of others who are better informed. ${ }^{108}$ Allowing experts to contribute to group discussions increases the whole group's ability. ${ }^{109}$ While Chappell largely talks about political decision-making, her arguments still illustrate how including other sources of information, like experts, can assist in broadening views. A group of individuals who have similar views on an issue is likely to use and accept arguments that advance that view, ${ }^{110}$ with little reference to other information or evidence. Hence the presence of an expert can encourage critical thinking about stereotypical arguments and present new points of view that may not have crossed the jury's mind when it comes to sexual assault. Experts will be able to temper incorrect beliefs about rape from other jurors by putting forward their views about the case during deliberation. It would open jurors to alternative views and diversify views on sexual assault in the jury than what would otherwise be the case, which is necessary to a well-functioning jury making a collective decision. Lay participants would further guard against the descent of discussions into professional disagreements, which is a potential issue in a panel composed solely of experts. Such a solution targets the issues of reliance on rape myths in collective decision-making, rather than abandoning collective decision-making altogether.

Nevertheless, such a model assumes people are willing to learn from those who are more knowledgeable and assumes beliefs will actually be changed by the presentation of good arguments that are contrary to their beliefs. ${ }^{111}$ Again, Chappell talks about political decision-making, arguing that personal interest in the outcome is relevant to willingness to change beliefs. ${ }^{112}$ She states that for this reason, criminal trials are different because there is no personal stake in the outcome so individuals have little incentive to change their views. ${ }^{113}$ However, this article argues that it is applicable to jury deliberations because opinions on society and crime are connected to how people act and what people value, so these kinds of decisions likewise have a personal interest dimension. Anonymity and inability to inquire about jury deliberations may also provide a level of privacy in which jurors will feel more comfortable changing their attitudes.

108 Zsuzsanna Chappell "Justifying Deliberative Democracy: Are Two Heads Always Wiser Than One?" (2011) 10 Contemporary Political Theory 78 at 85 .

109 At 85 .

110 At 94.

111 At 85

112 At 96

113 At 95 
In some respects, having experts on juries would lead to greater consistency because currently, due to random selection, misconceptions about sexual assault may be rife within some juries while others may be more enlightened. Having experts with background knowledge about the realities of sexual violence present in every jury would mean all juries would have at least some members who are capable of reasoning with less influence from rape myths, whereas presently it is luck of the draw as to whether more informed views are represented.

However, simply having knowledge in an area does not mean that experts are infallible. Confidence in beliefs by experts should not be taken as truth and opinions should still be scrutinised. ${ }^{114}$ Usually cross-examination serves this function. ${ }^{115}$ Questioning views allows the opinions and facts proposed by an expert to be tested. ${ }^{116}$ Having an expert providing information during deliberations eliminates the ability to cross-examine and check the validity of the views as a party would be able to do in court. In court, the need for cross-examination is important as it allows both sides to test theories and evidence and enables the jury to compare which side's narrative the evidence best fits, ${ }^{117}$ as well as assessing the validity of the expert's knowledge. ${ }^{118}$ While crossexamination may be a formal opportunity to have views tested, it is not the only way to ensure the soundness of an expert's conclusions.

Lay jurors would be able to challenge and question expert jurors, albeit in a less formal manner, so views would not be dictated and forced on ordinary jurors. Experts engaging in deliberations would also put them on the same level as jurors, rather than "preaching" to them. In a discussion format, experts may seem less unassailable, facilitating challenges to their views, thereby testing them. The presence of other jurors with different beliefs could to some degree provide a different vehicle for opinions to be challenged, as experts would need to justify and persuade others and respond to arguments to the contrary. Ordinary jurors may likewise encourage experts to reassess their opinions, just as experts may encourage ordinary jurors to consider their views. Additionally, if more than one expert was to be on each jury, potential differences in professional opinion could operate as another mechanism to scrutinise views.

Dynamic engagement between lay jurors and expert jurors would further ensure that jurors are not just listening passively to useful perspectives. As with judicial directions, jurors sometimes do not take in all relevant information. During deliberations, because lay jurors would have to respond to

114 Cunliffe, above n 98, at 164.

115 Steven Rares "Using the 'Hot Tub' - How Concurrent Evidence Aids Understanding Issues" (2012) 31 CJQ 30 at 30.

116 Mark Coen and Liz Heffernan "Juror Comprehension of Expert Evidence: A Reform Agenda" (2010) 3 Crim LR 195 at 210.

117 Law Commission, above n 14, at 55.

118 Edmond, above n 76, at 66 . 
experts in order to put their own views across (whether they concur with what the expert is saying or not), they are more likely to be actively engaged with the material. They are then more likely to think critically about it and assess its value.

Modifying the jury so it includes experts in the field of sexual violence will diversify the views in the jury room when it comes to sexual assault cases. The group decision-making process, which is a significant justification for the jury, is enhanced by guaranteeing that incorrect beliefs can be countered, ensuring the decision is based on evidence and facts. While admittedly there are some challenges due to the stubborn nature of false beliefs about rape, it allows jurors to be educated over a slightly longer period during discussions. Experts would also be able to respond to the specific views of jurors in real-time, adapting explanations and arguments to the particular group and reasoning put forward, unlike written information which may be put aside or not entirely on point. While there is a concern that views of experts will be unable to be cross-examined, this is to some degree limited by the ability of the rest of the jury to respond and engage in discussion. Lay jurors would also retain ultimate power in that numbers could be constructed so that experts alone would not be able to carry a vote, mitigating concerns that may be raised about elitism.

\section{CONCLUSION}

The jury is an iconic feature of the criminal justice system, and an institution that has endured for hundreds of years. Nevertheless, it should be open to adaptation when a problem with its function arises, such as in cases of sexual violence. The justice system should be wary of falling into the trap of "this is how it has always been done" despite clear issues. The current criminal justice system is falling short in its response to sexual assault victims, and while the jury is part of the problem, it can also be part of the solution.

Given the significant challenges facing the system in the area of sexual violence, adaptations should be made. External factors such as rape myths are misleading and should not have an impact on deliberations and decisions.

While there are options to change the fact-finder completely by making use of judge only trials or using experts in the place of juries, these solutions may not provide sufficient benefits to justify abandoning the jury. Moreover, juries have several functions that are important symbolically and practically which are in themselves admirable objectives not to be discarded lightly. Thus, attention should be directed to whether it is possible to improve, support, and build on the jury to ensure a fairer process to reduce extra-evidential influences without eliminating juries completely.

Options to support the jury more in their task, such as providing increased guidance and education, have many challenges and may not work to minimise the impact of rape myths on decision-making significantly. Instead, greater use should be made of experts, who rely less on erroneous beliefs because of their expertise in the area of sexual violence. 
While there are a few ways in which experts could be involved in court processes, targeting expert knowledge at the deliberation phase could improve jury discussions and ensure views that do not rely on rape myths are heard. Making the group decision-making process more robust in this way can be achieved through combining experts with jurors, forcing other jurors who accept rape myths to actively and continually question their biases. Such a solution also allows the information provided to jurors to debunk rape myths to be flexible and sensitive to the particular views of a given jury and issues at stake in a case. Dialogue would be a two-way discussion so that expert opinions are not unassailable. A dual model of lay people and professionals making factual determinations as part of the jury is an option which should be further explored to limit the impact of rape myths on jury deliberations. 